\title{
A baseline study of tropical coastal water quality in Port Dickson, Strait of Malacca, Malaysia
}

\begin{abstract}
Tidal variation in tropical coastal water plays an important role on physicochemical characteristics and nutrients concentration. Baseline measurements were made for nutrients concentration and physicochemical properties of coastal water, Port Dickson, Malaysia. $\mathrm{pH}$, temperature, oxidation reduction potential, salinity and electrical conductivity have high values at high tides. Principal Components Analysis (PCA) was used to understand spatial variation of nutrients and physicochemical pattern of Port Dickson coastal water at high and low tide. Four principal components of PCA were extracted at low and high tides. Positively loaded nutrients with negative loadings of DO, $\mathrm{pH}$ and ORP in PCA outputs indicated nutrients contribution related with pollution sources. This study output will be a baseline frame for future studies in Port Dickson involving water and sediment samples. Water and sediment samples of future monitoring studies in Port Dickson coastal water will help in understanding of coastal water chemistry and pollution sources.
\end{abstract}

Keyword: Coastal water; Nutrients; Physicochemical properties; Pollution; Baseline 